\title{
THE UTILIZATION OF INFORMATION TECHNOLOGY BASED LEARNING MEDIA IN LEARNING
}

\section{PEMANFAATAN MEDIA PEMBELAJARAN BERBASIS TEKNOLOGI INFORMASI DALAM PEMBELAJARAN}

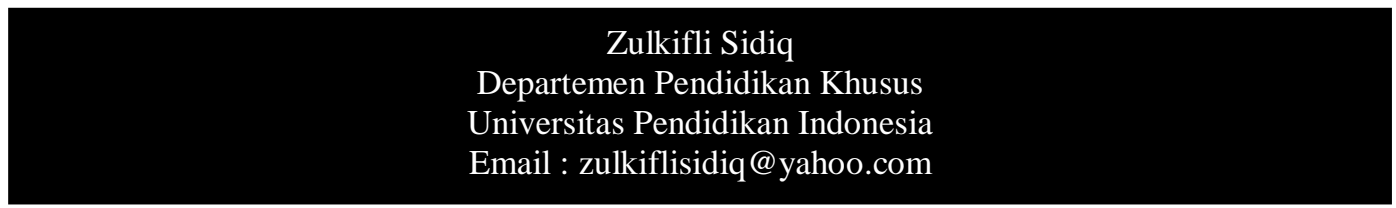

Abstract, The development of information technology has supported the learning process so that it can be conducted whenever and wherever. Thus, teacher does no longer become the central figure and school is no longer the only learning environment for students. Teacher and school are only facilitator and mediator in learning. IT based learning media makes learning process multidimensional and multi purposes. This research aims to find out teachers' perceptions on the utilization of IT based learning media. This research used survey method. The population was all primary school teachers in Cisaat district Sukabumi regency. The subjects were 45 teachers randomly chosen from schools in Cisaat district. The results showed that teachers' perception on the utilization of IT based learning media in increasing the learning quality was very positive with the percentage of $80.67 \%$; teachers' perceptions on the utilization of IT based learning media in expanding and improving access in learning was about $73.56 \%$; teachers' perceptions on the development of IT based learning media in improving teachers' professionalism was 78\%; and teachers' perceptions on the tendency of the utilization of IT based learning media in distance education model was about $71.41 \%$. Hence, it can be concluded that IT based learning program has an opportunity to be implemented in Cisaat district because the teachers already have good understanding about the function of IT based media in learning.

Keywords: media, information technology, teacher perception, learning

Abstrak, Perkembangan dunia saat ini menunjukkan kecenderungan bahwa dalam konteks pendidikan masa depan, setiap individu akan dihadapkan pada tantangan dan kebutuhan yang tidak akan sepenuhnya dapat terpenuhi melalui sistem pendidikan konvensional. Dalam konteks ini, dukungan perkembangan IT memungkinkan proses pembelajaran terjadi kapanpun dan dimanapun. Dengan demikian, guru tidak lagi menjadi figur sentral dan sekolah tidak lagi menjadi satu-satunya lingkungan belajar bagi peserta didik. Guru dan sekolah hanyalah fasilitator dan mediator pembelajaran. Media pembelajaran berbasis IT membuat proses pembelajaran bersifat multi dimensi dan multi purposes. Rumusan masalah yang dikaji dalam penelitian ini adalah bagaimana persepsi guru terhadap pemanfaatan media pembelajaran berbasis IT dalam pembelajaran. Jenis penelitian ini adalah penelitian survei. Populasi penelitian ini adalah seluruh Guru Sekolah Dasar di wilayah Kecamatan Cisaat Kabupaten Sukabumi. Dalam penelitian ini subyek penelitian ditetapkan adalah sebagian Guru yang dijadikan sampel penelitian yang mewakili wilayah Kecamatan Cisaat. Dalam hal ini, subyek penelitian ini terdiri dari 45 guru yang dipilih secara acak dari Sekolah Dasar Negeri di Wilayah Kecamatan Cisaat. Dari penelitian ini diperoleh kesimpulan bahwa skor persepsi media pembelajaran berbasis IT pada bagi guru Sekolah Dasar di wilayah Kecamatan Cisaat Kabupaten Sukabumi menunjukkan persepsi guru terhadap media pembelajaran berbasis IT dalam meningkatkan mutu pembelajaran menunjukkan persepsi sangat positif dengan nilai persentase sebesar $80.67 \%$, persepsi guru terhadap media pembelajaran berbasis IT dalam memperluas dan 
mempermudah akses terhadap pembelajaran dengan nilai persentase sebesar $73.56 \%$, persepsi guru terhadap pengembangan media pembelajaran berbasis IT meningkatkan profesionalisme guru dengan nilai persentase sebesar $78.00 \%$, dan persepsi guru terhadap kecenderungan penggunaan media pembelajaran berbasis IT dalam model pembelajaran jarak jauh dengan nilai persentase sebesar $71.41 \%$. Dengan demikian, program pembelajaran berbasis IT memiliki peluang untuk diimplementasikan di wilayah Kecamatan Cisaat Kabupaten Sukabumi karena guru telah memiliki pemahaman yang baik mengenai fungsi media berbasis IT dalam pembelajaran.

Kata Kunci : Media, Teknologi infomasi, persepsi, pembelajaran

\section{A. PENDAHULUAN}

Perkembangan dunia saat ini menunjukkan kecenderungan bahwa dalam konteks pendidikan masa depan, setiap individu akan dihadapkan pada tantangan dan kebutuhan yang tidak akan sepenuhnya dapat terpenuhi melalui sistem pendidikan konvensional. Di masa depan setiap individu harus menentukan keputusan mengenai apa dan bagaimana seharusnya ia belajar. Dengan demikian, iklim pembelajaran harus mulai diarahkan untuk transformasi situasi dari sebuah pembelajaran konvensional. sehingga dapat memberikan kontribusi yang signifikan bagi ketercapaian tujuan pendidikan. Proses pendidikan dan pembelajaran tidak hanya dituntut untuk mendorong peserta didik untuk belajar (to learn), tetapi juga dituntut untuk dapat mendorong peserta didik untuk belajar menguasai ilmu (learning to acquire knowledge), mempromosikan aktivitas belajar bertindak (learning to act), belajar hidup bersama (learning to live together), dan belajar untuk kehidupan (learning for life), dengan paradigma belajar sepanjang hayat (life long learnng). Proses pendidikan dan pembelajaran tidak bisa lagi sekedar menjadi tempat berlangsungnya transmisi informasi dari guru kepada murid dalam periode waktu dan batasan ruang tertentu. Lembagalembaga pendidikan dituntut untuk dapat berperan sebagai fasilitator bagi para pendidik dan peserta didik untuk mengembangkan aktivitas pembelajaran yang mobile, dinamis, dan menembus batasan ruang (spaceless), batasan waktu (timeless), dan batasan kenegaraan (borderless).

Dalam konteks ini, dukungan perkembangan IT memungkinkan proses pembelajaran terjadi kapanpun dan dimanapun. Dengan demikian, guru tidak lagi menjadi figur sentral dan sekolah tidak lagi menjadi satusatunya lingkungan belajar bagi peserta 
didik. Guru dan sekolah hanyalah fasilitator dan mediator pembelajaran. Sarana ICT membuat proses pebelajaran bersifat multi dimensi dan multi purposes. Dari pernyataan di atas menunjukkan bahwa IT sangat diperlukan dalam proses pembelajaran.

Teknologi informasi dan komunikasi di era globalisasi saat ini sudah menjadi kebutuhan yang mendasar dalam mendukung efektifitas dan kualitas proses pendidikan. Akan tetapi, perkembangan teknologi informasi atau multimedia di Indonesia khususnya dalam dunia pendidikan masih belum optimal. Hal ini ditunjukkan dengan masih adanya kendala baik teknis maupun non teknis yang masih menjadi fenomena dalam implementasi teknologi informasi di berbagai jenjang pendidikan baik formal maupun non formal.

Persepsi dan sikap guru tentang pemanfaatan media berbasis IT merupakan salah satu factor yang mempengaruhi peningkatan mutu pendidikan dalam konteks perkembangan IT ini. Kemampuan dan pemahaman guru terhadap pemanfaatan IT dalam pembelajaran dipengaruhi antara lain oleh persepsi. Persepsi positif guru akan menunjukkan kemampuan guru dalam memahami keberadaan dan fungsi media berbasis IT dalam mendukung efektifitas dan kualitas proses pendidikan dan pembelajaran.

1. Rumusan Masalah

Berdasarkan latar belakang di atas, maka masalah yang dikaji dalam penelitian ini adalah bagaimana persepsi guru terhadap pemanfaatan media pembelajaran berbasis IT dalam pembelajaran, yang dirumuskan dalam pertanyaan penelitian sebagai berikut :

a. Bagaimana persepsi guru terhadap penggunaan media pembelajaran berbasis IT dalam meningkatkan mutu pembelajaran (the delivery of quality learning and teaching)?

b. Bagaimana persepsi guru terhadap penggunaan media pembelajaran berbasis IT dalam memperluas dan mempermudah akses terhadap pendidikan?

c. Bagaimana persepsi guru terhadap pengembangan media pembelajaran berbasis IT meningkatkan profesionalisme guru (teachers' professional development)?

d. Bagaimana persepsi guru terhadap kecenderungan penggunaan media 
pembelajaran berbasis IT dalam model pendidikan jarak jauh?

2. Metodologi

Jenis penelitian ini adalah penelitian survei. Survei dilakukan untuk mendeskripsikan persepsi guru terhadap pembelajaran yang berbasis IT.Populasi penelitian ini adalah seluruh Guru Sekolah Dasar di wilayah Kecamatan Cisaat Kabupaten Sukabumi. Namun, dalam penelitian ini subyek penelitian ditetapkan adalah sebagaian Guru yang dijadikan sampel penelitian yang mewakili wilayah Kecamatan Cisaat. Dalam hal ini, subyek penelitian ini terdiri dari 45 guru yang dipilih secara acak dari Sekolah Dasar Negeri di Wilayah Kecamatan Cisaat Setiap guru diberikan instrumen yang sudah disiapkan oleh peneliti. Instrumen ini berupa angket untuk melihat persepsi guru terhadap media pembelajaran berbasis IT

\section{B. HASIL DAN PEMBAHASAN}

Berdasarkan data penelitian untuk skor persepsi terhadap media pembelajaran berbasis IT di Kecamatan Cisaat Kabupaten Sukabumi dengan rentang teoretis $0-55$ diperoleh skor empiris 32 - 51. Disitribusi ini memberikan skor rata-rata (x) sebesar 41.73. Dengan rentang skor teoretis 055 yaitu minimum sebesar 0 dan skor maksimum sebesar 55. maka nilai tengah teoretis sebesar 43. Dengan demikian, skor rata-rata data persepsi guru terhadap media pembelajaran berbasis TI sebesar 41.73 berada pada interval skor rata-rata. Hal ini memberikan gambaran bahwa data lebih terpusat pada daerah rata-rata. Dengan demikian dapat dimaknai bahwa guru Sekolah Dasar di Kecamatan Cisaat Kabupaten Sukabumi memiliki persepsi positif terhadap media pembelajaran berbasis IT.

Berikut adalah rekapitulasi pengolahan data mengenai persepsi guru Sekolah Dasar di Kecamatan Cisaat Kabupaten Sukabumi terhadap media pembelajaran berbasis IT. 
Tabel. 1 Rekapitulasi Hasil Pengolahan Data

\begin{tabular}{cc}
\hline & Nilai \\
\hline Mean (Rata-rata) & 41.73 \\
Varians & 23.78 \\
Simpangan Baku & 3.8 \\
\hline
\end{tabular}

Sebaran mengenai skor persepsi berbasis IT juga dapat ditampilkan guru terhadap media pembelajaran pada grafik berikut ini.

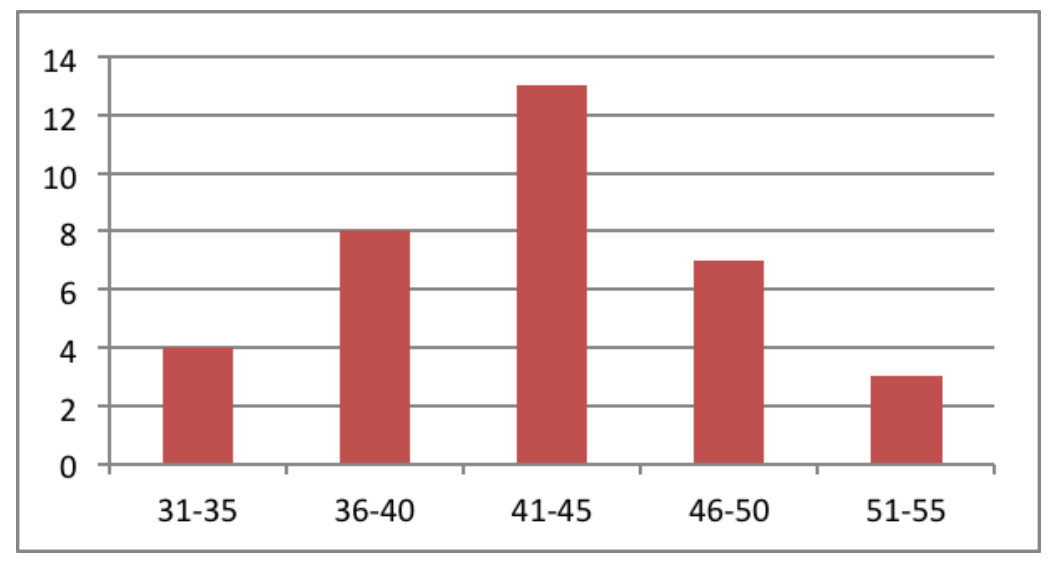

Grafik 1.1 Sebaran Skor Persepsi Guru Sekolah Dasar terhadap media pembelajaran berbasis IT di Kecamatan Cisaat Kabupaten Sukabumi.

Adapun persepsi terhadap media Kabupaten Sukabumi pada setiap pembelajaran berbasis IT pada guru aspeknya dapat dilihat pada grafik Sekolah Dasar di Kecamatan Cisaat berikut ini.

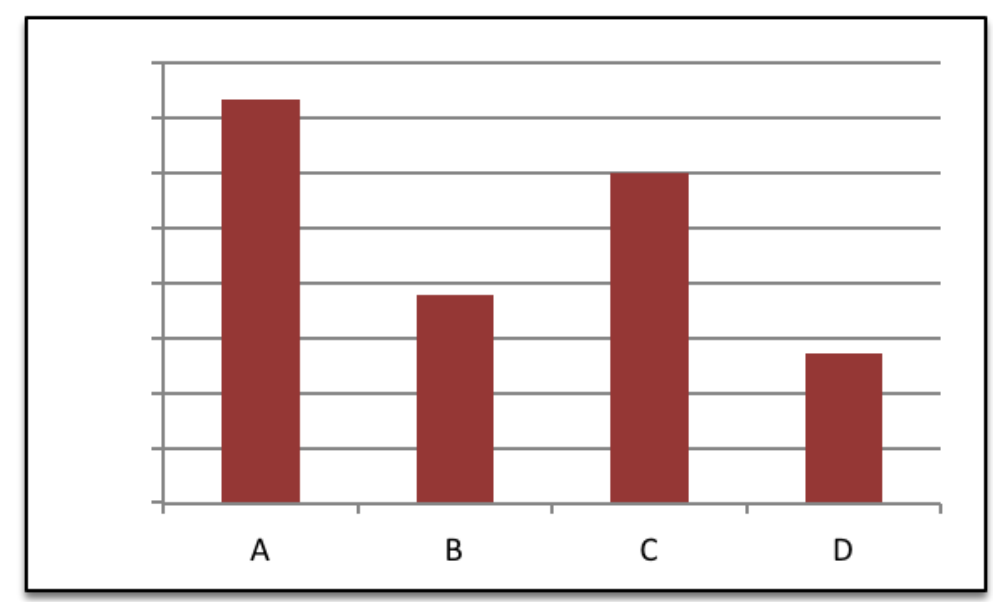

Grafik 2.1

Persepsi terhadap media pembelajaran berbasis IT pada guru Sekolah Dasar di Kecamatan Cisaat Kabupaten Sukabumi pada setiap aspeknya 
Keterangan :

$\mathrm{A}=$ Aspek media pembelajaran berbasis IT dalam meningkatkan mutu pembelajaran (the delivery of quality learning and teaching)

$\mathrm{B}=$ Aspek media pembelajaran berbasis IT dalam memperluas dan mempermudah akses terhadap pembelajaran

$\mathrm{C}=$ Aspek pengembangan media pembelajaran berbasis IT meningkatkan profesionalisme guru (teachers' professional development)

$\mathrm{D}=$ Aspek kecenderungan penggunaan media pembelajaran berbasis IT dalam model pembelajaran jarak jauh

Dari grafik tersebut menunjukkan bahwa pada aspek media pembelajaran berbasis IT dalam meningkatkan mutu pembelajaran (the delivery of quality learning and teaching), persepsi guru Sekolah Dasar di Kecamatan Cisaat Kabupaten Sukabumi menunjukkan persentase sebesar $80.67 \%$ yang bermakna bahwa guru-guru tersebut memiliki persepsi yang sangat positif terhadap media pembelajaran berbasis IT dalam meningkatkan mutu pembelajaran (the delivery of quality learning and teaching). Pada aspek media pembelajaran berbasis IT dalam memperluas dan mempermudah akses terhadap pembelajaran, hasil penelitian menujukkan nilai persentasi sebesar $73.56 \%$ yang bermakna bahwa guru Sekolah Dasar di Kecamatan Cisaat Kabupaten Sukabumi juga memiliki persepsi positif bahwa keberadaan media pembelajaran berbasis IT dapat memperluas dan mempermudah akses terhadap pembelajaran. Begitupun pada aspek pengembangan media pembelajaran berbasis IT meningkatkan profesionalisme guru (teachers' professional development) dan aspek kecenderungan penggunaan media pembelajaran berbasis IT dalam model pembelajaran jarak jauh menunjukkan persepsi positif dengan nilai persentase sebesar $78.00 \%$ dan $71.41 \%$. 
Tabel 2.1

Kategori Persepsi Guru Sekolah Dasar terhadap media pembelajaran berbasis IT di Kecamatan Cisaat Kabupaten Sukabumi.

\begin{tabular}{|c|c|c|c|c|}
\hline No & Aspek & $\begin{array}{l}\text { Skor } \\
\text { rata- } \\
\text { rata }\end{array}$ & $\%$ & Interpretasi \\
\hline 1 & $\begin{array}{l}\text { media pembelajaran } \\
\text { berbasis IT dalam } \\
\text { meningkatkan mutu } \\
\text { pembelajaran (the } \\
\text { delivery of quality } \\
\text { learning and teaching) }\end{array}$ & 4.07 & 80.67 & $\begin{array}{l}\text { Sangat } \\
\text { positif }\end{array}$ \\
\hline 2 & $\begin{array}{l}\text { media pembelajaran } \\
\text { berbasis IT dalam } \\
\text { memperluas dan } \\
\text { mempermudah akses } \\
\text { terhadap pendidikan }\end{array}$ & 3.7 & 73.56 & Positif \\
\hline 3 & $\begin{array}{l}\text { Persepsi guru terhadap } \\
\text { pengembangan media } \\
\text { pembelajaran berbasis } \\
\text { IT meningkatkan } \\
\text { profesionalisme guru } \\
\text { (teachers 'professional } \\
\text { development) }\end{array}$ & 3.96 & 78.00 & Positif \\
\hline 4 & $\begin{array}{l}\text { kecenderungan } \\
\text { penggunaan media } \\
\text { pembelajaran berbasis } \\
\text { IT dalam model } \\
\text { pendidikan jarak jauh }\end{array}$ & 3.66 & 71.41 & Positif \\
\hline
\end{tabular}

Secara umum, hasil penelitian Uraian tersebut menunjukkan menunjukkan persentasi rata-rata bahwa responden (guru) memiliki persepsi guru terhadap media persepsi yang positif terhadap media pembelajaran berbasis IT sebesar pembelajaran berbasis IT, paling tidak 75.88\%. Data tersebut memberikan guru telah memilki ide dan konsep, gambaran bahwa secara umum guru- memahami perlunya pembelajaran guru Sekolah Dasar di Kecamatan berbasis IT. Jika dilihat dari aspek Cisaat Kabupaten Sukabumi memiliki pemahaman dan pemanfaatan media persepsi positif terhadap media belajar berbasis IT, maka terlihat pembelajaran berbasis IT. bahwa para responden masih 
mengganggap aspek media kelas setiap hari dan mengevaluasi pembelajaran berbasis IT dalam untuk menentukan dampak pengajaran meningkatkan mutu pembelajaran (the pada mental, perasaan dan nilai-nilai, delivery of quality learning and keterampilan personal, dan teaching) lebih dominan dibanding tiga keterampilan motorik.

aspek lainnya.

Akan tetapi, persepsi guru yang

Meskipun beberapa diantara para menyatakan bahwa penggunaan media guru tersebut belum memiliki pembelajaran berbasis IT dalam kemampuan menggunakan media meningkatkan mutu pembelajaran (the berbasis IT, persepsi yang positif dari delivery of quality learning and responden ini memberikan indikasi teaching) tentu harus diimbangi dengan bahwa penerapan dan pemanfaatan IT pemahaman yang baik dalam di Sekolah Dasar di wilayah pemanfaatan media tersebut. Penelitian Kecamatan Cisaat Kabupaten perbandingan media selama beberapa Sukabumi memiliki peluang besar dekade menunjukkan bahwa "no media untuk dikembangkan, karena guru telah is globally 'better' than another'. Hasil memahami perlunya penggunaan penelitian tersebut menunjukkan bahwa media berbasis IT dalam diperlukan berbagai pertimbangan pembelajaran.

Berbagai pendapat menjelaskan seorang guru dalam memilih media yang sesuai.

Selain itu, perlu dipahami bahwa dampak positif terhadap proses media bukanlah bagian integral dalam pembelajaran yang disebut Mayer sebuah pembelajaran, media pada (2006:116) sebagai multimedia effect. dasarnya adalah sebuah carriage yang Lebih dari itu, Smaldino, Lowther and keberhasilan sebuah media untuk dapat Sussel (2011) menjelaskan media dapat menyampaikan pesan ditentukan oleh : menjadi katalis perubahan dalam 1. Pendekatan yang digunakan sebuah lingkungan belajar. Akan tetapi, (cognitive, humanism, cybernetic etc.), media yang efektif mengharuskan 2. Content (isi pesan/informasi), 3. instruktur harus lebih siap dari Strategi yang digunakan, 4. sebelumnya, memikirkan tujuan Learner/receiver (meliputi mereka, mengubah rutinitas ruang communication skill, knowledge, 
culture, social system dan attitude), dan 5. Konteks lingkungan. Hal ini dipertegas oleh Clark (1983) dalam Simonson et.al (2012) yang menyatakan the best evidence is that media are mere vehicle that deliver instruction but do that influence student achievement any more than the truck that deliver our groceries causes changes in nutrition...only the content of the vehicle can influence achievement

Di sisi lain, dalam konteks dunia pendidikan masa depan, semua anak akan dihadapkan pada tantangan dan kebutuhan yang tidak akan terpenuhi melalui system pendidikan konvensional. Di masa depan, semua anak harus memiliki tujuan pembelajaran masing-masing, merencanakan apa yang harus mereka pelajari dan mengelola waktunya sendiri. Dengan demikian, penggunaan media pembelajaran berbasis IT dapat dirancang agar kondusif untuk semua karakter pembelajar. Teknologi dapat digunakan sebagai pendekatan pembelajaran untuk mengidentifikasi siapa siswa yang memerlukan pelayanan khusus sehingga terjadi pembelajaran yang kontruktivitis, proaktif dan menghasilkan umpan balik yang dapat memotivasi siswa untuk belajar lebih baik. Dengan demikian media pembelajaran berbasis IT dalam memperluas dan mempermudah akses terhadap pendidikan.

Akan tetapi, terdapat hal penting yang harus dipertimbangkan adalah bagaimana agar teknologi dapat digunakan dalam cara yang tepat sehingga memberikan manfaat dalam pembelajaran. Pendekatan teknologi harus difokuskan pada masalah belajar agar memastikan bahwa sekolah dan system yang ada menjadi efisien. Hess and Saxberg (2014) menjelaskan bahwa prinsip-prinsip penting untuk mendesain ulang system dan sekolah adalah dengan membuat perbaikan sekolah melalui teknologi tepat guna, selanjutnya perlu juga membuat komunitas pembelajar yang professional yang memungkinkan pendidik dapat bekerjasama. Prinsip selanjutnya adalah pembelajaran beragam yang harus disesuaikan dengan minat, motivasi dan kemampuan masing-masing siswa. Dengan demikian, media pembelajaran berbasis IT juga harus dilakukan pada hal yang sifatnya operasional seperti bahan ajar yang terstruktur, bersifat individualdan bahan ajar dalam bentuk 
fisik yang mudah diakses. Hess and Saxberg (2014) juga menjelaskan bahwa era digital masa depan adalah sebuah peluang baru yang akan mendukung proses pembelajaran menjadi lebih baik, perlu dilakukan tranformasi yang dapat meningkatkan pembelajaran.

Dalam hal ini, profesionalisme guru tidak hanya mencakup kemampuan membelajarkan siswa, tetapi juga kemampuan seorang guru dalam mengelola informasi dan lingkungan belajar sehingga proses pembelajaran lebih efektif.

Perkembangan ilmu pengetahuan dan teknologi, khususnya IT, telah memperkaya sumber dan media pembelajaran dalam berbagai bentuk mulai dari bahan cetak sampai media pembelajaran berbasis web. Semua ini menuntut guru yang profesional agar mampu memilih, mengembangkan dan memanfaatkan berbagai jenis media pembelajaran berbasis IT tersebut.

Media pembelajaran berbasis IT memungkinkan pesan timbal balik balik antara pemberi dan penerima pesan. Suparman (2014) juga menjelaskan bahwa kepercayaan orang akan kemampuan teknologi dalam menyimpan serta memunculkan kembali tanpa terpengaruh oleh tempat, waktu, dan jarak, menjadi semakin besar dan kepercayaan ini akan menambah frekuensi penggunaan teknologi tersebut dari waktu ke waktu. Akan tetapi, efektivitas penggunaan media berbasis IT dalam pendidikan jarak jauh juga sangat dipenggaruhi oleh kapasitas pengajar dan peserta didik dalam menggunakananya, seperti yang dijelaskan Simoson, et. al (2012) bahwa the effective utilization of distance classrooms requires a new set of skills for most educators and learners.

\section{KESIMPULAN}

Berdasarkan deskripsi data dan pembahasan hasil penelitian seperti yang telah dikemukakan di atas, maka dapat disimpulkan bahwa berdasarkan data penelitian untuk skor persepsi media pembelajaran berbasis IT pada bagi guru Sekolah Dasar di wilayah Kecamatan Cisaat Kabupaten Sukabumi sebagai berikut : a) Persepsi guru terhadap media pembelajaran berbasis IT dalam meningkatkan mutu pembelajaran (the delivery of quality learning and teaching) di Kecamatan Cisaat Kabupaten Sukabumi menunjukkan persepsi sangat positif . 
Edutech, Tahun 15, Vol.15, No.1, Februari 2016

b) Persepsi guru terhadap media pembelajaran berbasis IT dalam memperluas dan mempermudah akses terhadap pembelajaran di Kecamatan Cisaat Kabupaten Sukabumi menunjukkan persepsi sangat positif. c) Persepsi guru terhadap pengembangan media pembelajaran berbasis IT meningkatkan profesionalisme guru (teachers' professional development) di Kecamatan Cisaat Kabupaten Sukabumi menunjukkan persepsi positif. d)Persepsi guru terhadap kecenderungan penggunaan media pembelajaran berbasis IT dalam model pembelajaran jarak jauh di Kecamatan Cisaat Kabupaten Sukabumi menunjukkan persepsi positif .

1. Rekomendasi

$$
\text { Program-program pembelajaran }
$$
berbasis IT memiliki peluang untuk diimplementasikan di wilayah Kecamatan Cisaat Kabupaten Sukabumi karena guru telah memiliki pemahaman yang baik mengenai fungsi media berbasis IT dalam pembelajaran.

\section{DAFTAR PUSTAKA}

Hess, F.M and Saxberg B. (2014). Breakthrough Leadership in The Digital Age : Using Learning Science to Reboot Schooling.
Thousand Oaks. California : Corwin.

Mayer, Richard E. (2009). Multi-Media Learning. Prinsip-Prinsip dan Aplikasi. Surabaya: ITS Press.

Simoson, M. et.al. (2012). Teaching and Learning at a Distance. Boston : Pearson Education Inc.

Smaldino, S., Lowther, D., Sussel. (2011). Instructional Technology \& Media for Learning (terj.) Jakarta : Media Prenada Grup.

Suparman, Atwi. 2014. Teknologi Pendidikan dalam Pendidikan Jarak Jauh. Jakarta : Universitas Terbuka. 